\title{
Seasonality and Distribution of Whale Calls in the North Pacific
}

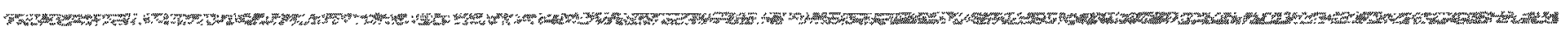

William A. Watkins, Mary Ann Daher, Gina M. Reppucci, Joseph E. George, Darel L. Martin,

Nancy A. DiMarzio, and Damon P. Gannon

Woods Hole Oceanographic Institution • Woods Hole, Massachusetts USA

$\mathbf{M}$

ost descriptions of sounds produced by whales at sea have been described from scattered, unsystematic observation and recording of animals during shipboard encounters. Such encounters provide data on only a few individuals in isolated locations. Since the original scientific recordings of cetaceans by Schevill and Lawrence $(1949,1950)$, about 70 species have been recorded and calls catalogued (Schevill and Watkins, 1962; Watkins and Wartzok, 1985; Watkins et al., 1991). These include calls recorded close to whales and those monitored remotely over extended periods from the three species whose sounds are analyzed here: blue whales, (Balaenoptera musculus, Cummings and Thompson, 1971; Thompson and Friedl, 1982; McDonald et al., 1995; Clark and Fristrup, 1997; Rivers, 1997) fin whales (Balaenoptera physalus, Schevill et al., 1964; Watkins, 1981; Thompson and Friedl, 1982; Watkins et al., 1987), and humpback whales (Megaptera novaeangliae, Payne and McVay, 1971; Tyack, 1981; Payne et al., 1983). These previous studies provided the basis for confident recognition of the calls of these species.

Although observation of whale acoustic behavior from shipboard has provided the positive attribution of calls to the different species, it often has been complicated by the animal response to vessel noise, by limited and variable visibility, by variation in sound propagation, by local sea surface noise, and by climate and weather at different seasons and geographic locations. In contrast, bottom-mounted, offshore hydrophone systems are inherently non-disturbing, and allow consistent monitoring of calling whales regardless of weather, or daylight. Sounds recorded by such systems represent normal whale activity, affected only by competing noise and acoustic propagation pathways between deep hydrophones and sources that are usually distant and relatively near-surface.

Offshore hydrophone arrays accessed through the U.S. Navy Sound Surveillance System (SOSUS) were used previously to describe whale calling in the Atlantic (Clark 1995; Clark et al., 1993; Nishimura and Conlon, 1994), and in the Pacific (Northrop et al., 1971; Cummings and Thompson, 1994; Stafford et al., 1998; Moore et al., 1998). Calling whales have been tracked for long periods (blue whale for 43 days in the Atlantic, Gagnon and Clark 1993; unusual whale for 63 days in the Pacific, Watkins et al., 1993).

\section{Offshore Arrays Monitor Calling}

For our analyses here, acoustic data from similar offshore arrays in the North Pacific were used to describe the relative distribution and seasonality of particular whale call sequences during 1996 and 1997. Whale call data were accessed through the U.S. Navy Ocean Processing Facility (NOPF) on Whidbey Island, Washington. Locations for many of the systems remain protected, as are their characteristics and associated data processing. Arrays were bottom mounted with a variety of sensor configurations. To provide comparable information from all arrays, the beam-formed array data were interpolated to provide the equivalent of 40 line array beams (bi-directional) for each array. Array orientations were not considered for these analyses. The occurrence of calling by whales was assessed from the beam-formed spectrographic data for ten arrays selected to provide representative coverage for four offshore regions along the continental margins of the North Pacific. These offshore regions encompassed 2 million $\mathrm{km}^{2}$ or less, and were labeled NW, NC, NE, and SE (Figure 1, divided at increments of $30^{\circ}$ long. by $15^{\circ}$ lat.). Within these regions, some north-south detail in the data was provided by the use of two or three arrays located at different latitudes. Arrays in each region were labeled from the north (SE1 north of SE2 in SE region, etc.), with apparently little overlap in the usual calling occurrence data. There were two arrays each in the NW and NC regions and three (potentially $1 / 3$ more observations) in the NE and SE regions. 


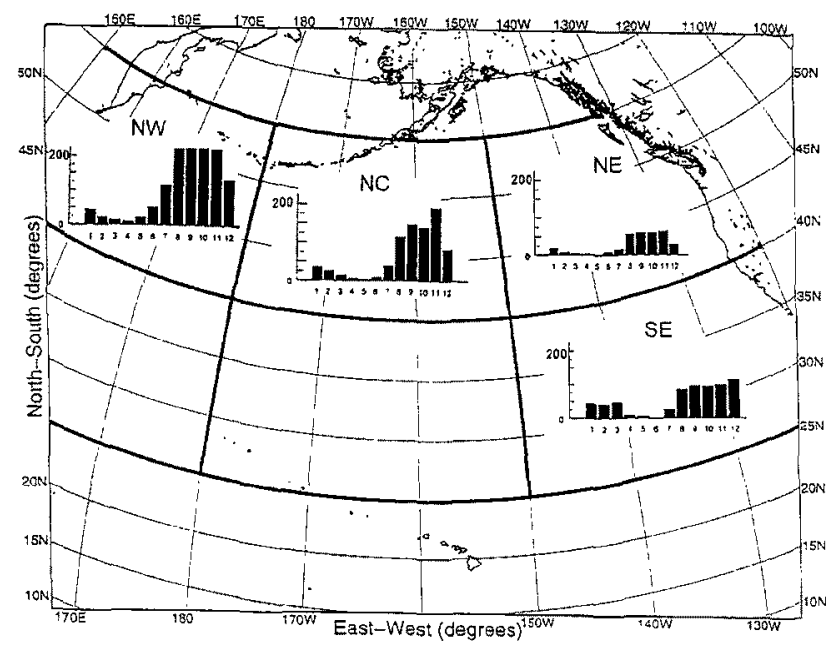

Figure 1 - Blue whale monthly calling averages during 1996 and 1997 indicated sensonal variations in the four offshore regions bordering continental margins of the North Pacific, each encompassing about 2 million $\mathrm{km}$ $\left(30^{\circ}\right.$ long. by $15^{\circ}$ lat. regions outlined and labeled NW, NC. NE, and SE). Insets show occurrences of blue whale calling averaged for each of the 12 months. NE and SE regions each had one nore array (potentially 1/3 more observations) than the NW and NC rogions.

Arrays were monitored by analysts with more than 20 years experience working with these systems and with spectrographic display of beam-formed analyses of such sounds. Whale call identifications were reviewed regularly by WHOI researchers with 10 to 40 years experience with such sounds. For occurrence of calling by the different species, spectrographic analyses of the acoustic data from all beams for each of the ten arrays were monitored systematically over the same period during two, usually consecutive, 16-hour days every week, centered on $1200 \mathrm{~h}$ GMT, spanning both daylight and darkness in each region. Calls of one to five whales of the same species distinguished on the same beam within 4 hours were considered one occurrence, and no new occurrence was logged for that day unless it was obvious that another set of calls had begun from a markedly different distance (sharp difference in level and acoustic pattern). Only one dominant beam displaying the calls was identified for each occurrence. Four call occurrences were possible during the 16-hour day from each array beam, but call sequences often continued over much of the day, and therefore, usually were recorded as one occurrence. If similar call sequences were present on the same array beam on the second day, they were recorded as another occurrence. When there were too many whales (six or more, usually many more) of apparently the same species to separate, this concentrated calling noise which usually lasted for most of the day was recorded as one " $\mathrm{J}$ " occurrence (such noise was traditionally called "Jezz" by Navy analysts). When call sequences with acoustic patterns and spectra identifiable to blue, fin, and humpback whales were noted, these were logged as a single call occurrence for each species, and any background calling from other whales of the same species was not recorded. Thus, the number of occurrences of whale calling did not provide a count of calling individuals or of the number of calls. Instead, they indicated the number of new call sequences within a minimum of 4 hours from each species. These were identified on any of 40 beams for each of the different arrays in the four regions of interest during the sampling period. These data provided a comparative measure of calling by each species and of the variations in calling with season and location.

Supplemented by data from additional arrays, these primary arrays also were used to assess source locations when the same call could be verified (detailed spectrograms superimposed) as being received on two or more arrays. Triangulation using the directions for sound reception from the different hydrophone systems provided estimates of sound source positions. Multiple positions for successive call sequences from individual whales allowed refinement of positions and tracking of their movements. The location of areas with concentrated calling apparently from numbers of whales also could be observed to change over time as local groups of calling whales moved, over days or weeks.

Whale calls that were received best were low frequency (propagating well) and repetitive with tonal characteristics (distinguishable from ambient noise). Less repetitive and transient sounds readily masked by noise were not a part of these analyses. The whale calling data analyzed here included species identification, occurrence of calling, and received beam without consideration of array orientation.

Calls from blue whales (Balaenoptera musculus), fin whales (Balaenoptera physalus), and humpback whales (Megaptera novaeangliae) were clearly identified on spectrographic displays of the beam-formed acoustic data from the hydrophone arrays. The occurrence of whale calls from each species was different in the four regions, varying with season and changing patterns of calling. Call occurrence was consistent between years, with generally similar patterns of calling recorded from the same array beams during the same periods of 1996 and 1997.

\section{Blue Whale Calling}

The blue whale call sequences that were identified were their long series of repetitive, downswept tonal calls with fundamental frequencies usually below $20 \mathrm{~Hz}$ and several harmonics, repeated variably at 3 to 10 minute intervals, often over several hours (i.e., McDonald et al., 1995; Clark and Fristrup, 1997; Rivers, 1997). Shorter calls from this species (i.e., Thompson et al., 1996) were not consistently separable from noise and so were not a part of these analyses. The function of these call sequences is not known. The seasonal occurrence (Figure 1) of blue whale calling is averaged for 


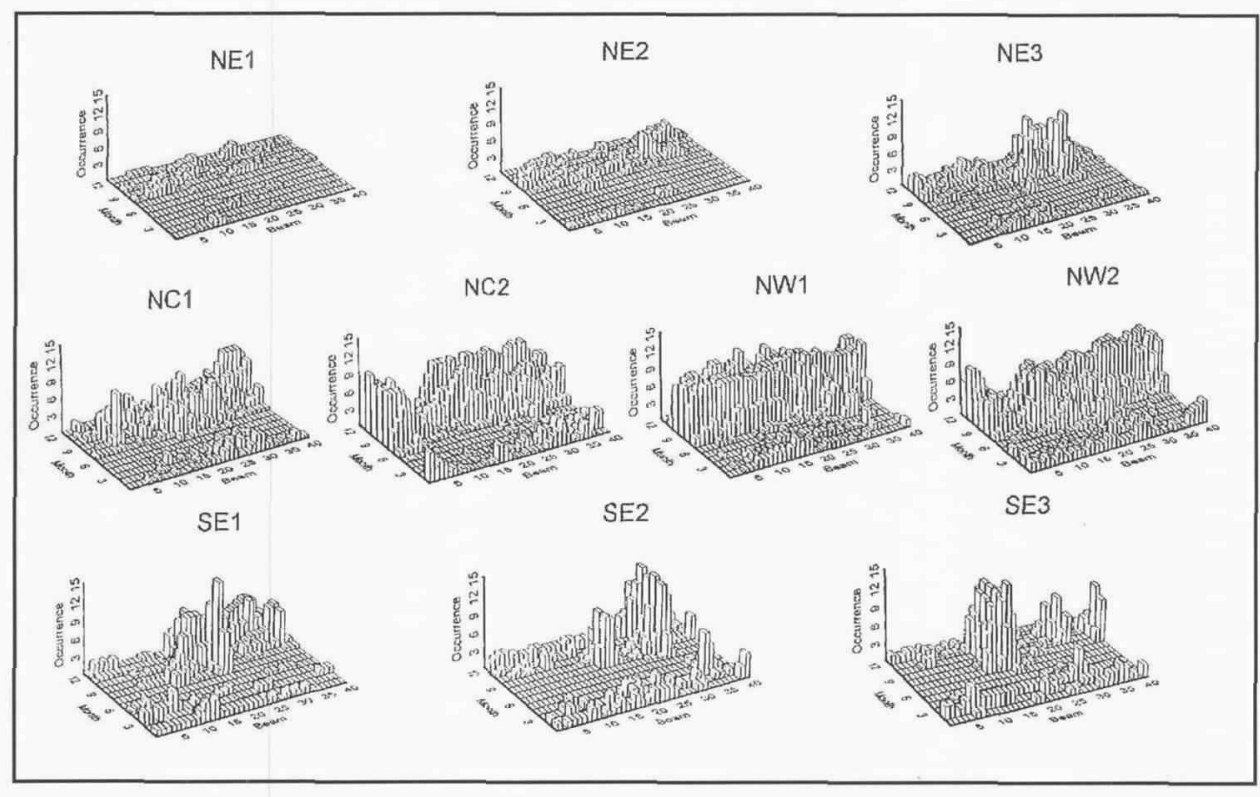

Figure 2 - Blue whale call sequences during 1996 and 1997 were averaged for each of 40 beams for all arrays in the four regions (NW, NC, NE, and SE) and plotted for the 12 months. Values indicate relative number of occurrences of calling received by the different arrays. In each region, arrays were labeled from the north (SE1 north of SE2 in the SE region, etc.).

each month over the two years for each of the four regions (labeled NW, NC, NE, and SE). Calling blue whales were recorded in all areas. Peak calling was during autumn, with little in spring and early summer. Calling blue whales occupied all four of these regions from late summer until early winter.

The distribution of blue whale call sequences relative to the receiving beams of the different arrays (Figure 2) were averaged for each month over the two years to show the variation in local distribution of calling whales from month to month for each region. Although array orientations were not considered, differences in occurrence of calling whales on the different array beams showed the relative scatter or grouping of calling indicative of their distribution in each region. In the NE region, there were more calling blue whale in the southern portion (NE3), and although scattered, they were received most from a particular area. Calls were similarly grouped and a bit more numerous in all portions of the SE. They were more evenly scattered and numerous in the NC, with most received in the southern portion (NC2). Calling was most numerous in the NW, with most in the northern portion (NW1), and there was about the same amount of calling on all beams (from all directions), indicating calling blue whales scattered widely and consistently over this entire region. Most occurrences of calling were from 1 to 5 whales with a few periods (not plotted separately), which included many overlapping call sequences on individual beams, again indicative of a considerable number of blue whales distributed widely.

Source locations for call sequences that could be identified on more than one array and the directions from hydrophone arrays for calling blue whales confirmed their generally scattered distribution. Blue whale call sequences often were received over distances of $500 \mathrm{~km}$ or more. There was evident movement of these whales from the southeast at the beginning of the peak calling period and returning toward the southeast at the end.

\section{Fin Whale Calling}

The fin whale call sequences that were identified were the repetitive, downswept " $20 \mathrm{~Hz}^{\prime}$ pulse series with most energy near or just above $20 \mathrm{~Hz}$ and little harmonic energy. Pulses were repeated regularly at rates of a few seconds in characteristic temporal patterns with three or four rests of a few minutes each hour over periods of 16 hours or more. These characteristic fin whale pulse series have been described in detail. Our shipboard observations (unpublished) during more than 60 acoustic tracks identifying and observing calling fin whales have consistently found only males (14-16 m, never the 18-20 m mature females) producing these call sequences, apparently as breeding displays (Schevill et al., 1964; Watkins, 1981; Watkins et al., 1987), analogous to the songs of male humpback whales (i.e., Tyack, 1981). The social and other more transient sounds from fin whales (Schevill and Watkins, 1962; Watkins, 1981) were not as reliably distinguishable from

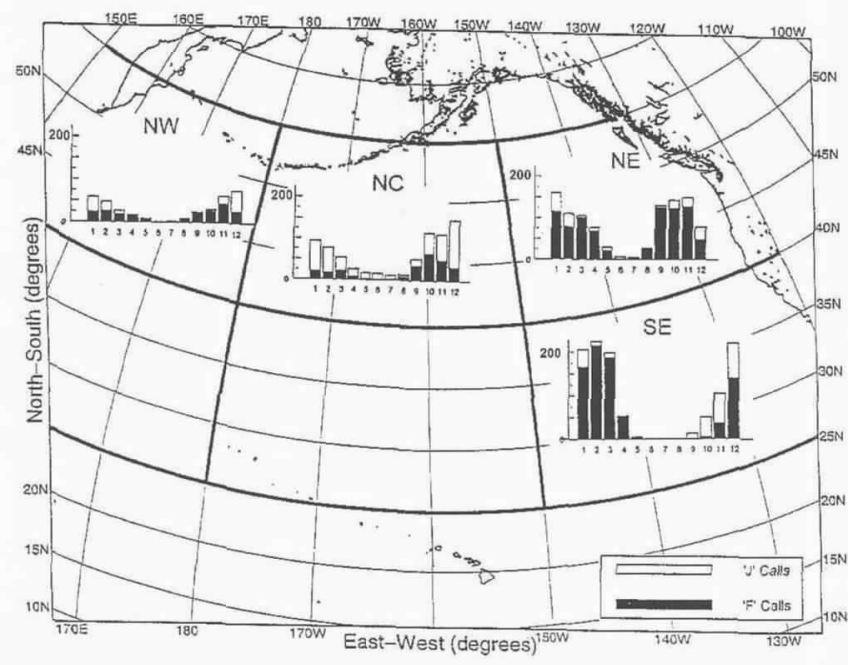

Figure 3 - Fin whale monthly calling averages during 1996 and 1997 indicated seasonal variations in the four offshore regions, NW, NC, NE, and SE. Insets show relative number of occurrences of calling averaged for each of the 12 months. NE and SE regions each had one more array than NW and NC. The " $F$ " calling (identifiable from individuals) and " $J$ " calling components (from too many whales to separate) are distinguished in the plots. 
noise in the usual array data, although sometimes they were received well from whales close to hydrophones (i.e., Moore et al., 1998). Fin whale calling data analyzed here included call sequences that could be reliably distinguished as coming from (1-5) individuals (labeled " $\mathrm{F}$ ") and overlapping call sequences from too many whales to allow separation (labeled "J"). The J component swamped concurrent calling by individuals, unless they were relatively close to arrays. Combining $\mathrm{F}$ and J components provided a more realistic picture of the distribution of fin whale calling, although no estimates could be made of the numbers of calling whales.

Fin whale calling (Figure 3) was averaged for each month during 1996 and 1997 to show the seasonal occurrence in each region. Fin whale calling was identified in all these deep-water regions, with the largest amount in the east (NE and SE). The peak calling period was

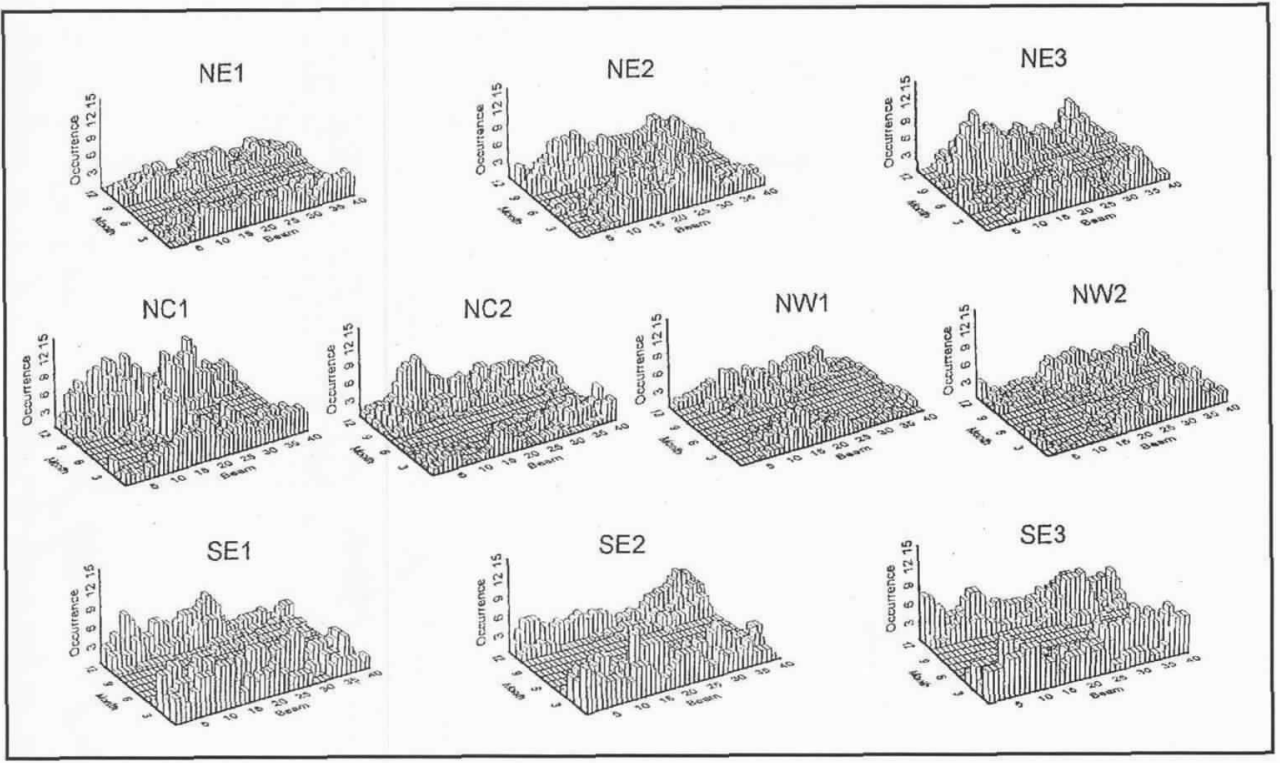

Figure 4 - Fin whale call sequences during 1996 and 1997 were averaged for each of 40 array beams and plotted for the 12 months as relative numbers of occurrences of calling received by the different arrays in the four regions. Arrays in each region are labeled from the north (SE1 north of SE2).

midwinter, two to three months later than the peak of blue whale calling. Few of these call sequences from fin whales were noted during the summer season.

The generally clumped distribution of calling fin whales is shown (Figure 4) by comparison of call occurrence (both $\mathrm{F}$ and $\mathrm{J}$ calls) relative to the receiving beams for the different arrays in each region averaged for each month over the two years. Most calling was in the central and southern areas of the NE (NE2, NE3), the SE (all areas), and in the northern area of the NC (NC1). There were far fewer occurrences of fin whale calling in the NW. Calling was variable from different directions and changed from month to month, sometimes grouped on particular sets of beams, indicating numbers of whales in variable groups calling as they moved slowly about local areas.

Source locations for call sequences that could be matched on more than one array and the directions noted to groups of calling whales from different arrays confirmed that during periods of intense calling, fin whales were concentrated in local areas, in contrast to the broadly scattered calling blue whales. Fin whale call sequences were received over relatively short distances estimated generally at less than $400 \mathrm{~km}$. Source locations for call sequences from individuals and changes in the areas occupied by calling whales provided no indication of migratory movements, only minor shifts in the concentrations of calling whales during the season.

\section{Humpback Whale Songs}

Humpback whale song components could be recognized reliably, although only the frequencies below a few hundred Hertz were typically received. Songs have been well described and identified as male reproductive displays, best known from calving and breeding aggregations near-shore, such as off Hawaii (i.e., Tyack, 1981; Payne et al., 1983). Songs were noted first in early December in the north of $\mathrm{NC}$ region (NC1) and occasionally in the south of the NE region (NE3). Then, humpback whale singing began in earnest in the middle of the SE region and southward (SE2 \& SE3) and continued in these areas until May (Figure 5). Singing peaked during early January and early May, but continuing in these deep water areas throughout the intervening months. No songs were recorded after the middle of May in any region. The occasional humpback songs noted in the NW region did not appear to be related to those in the SE.

The local distribution of singing humpbacks in the SE region (left inset Figure 5) is shown by the occurrence of songs relative to the array beams, averaged for each month of 1996 and 1997. Songs were received mostly in central (SE2) and southern (SE3) areas of the SE, with only a few in the northern area (SE1). Most humpback whales evidently began and ended singing as they moved through the middle of this region. Song sequences from apparently the same whales received on successive beams, as well as successive source locations for sequential calls apparently from the same whale, allowed assessment of direction of movements. December/January movements were southward, May movements were northward, and both northward and southward movements were noted in the intervening months. Reception of humpback songs usually appeared to be limited in distance to a few hundred kilometers. 


\section{Summary and Comment}

For these deepwater regions bordering the continental margins of the North Pacific, blue whale calling was strongest in the NW apparently from widely scattered whales, indicated by the broad spread in the received directions. The data demonstrate that there were significant numbers of blue whales distributed widely in the North Pacific especially during the fall season. The changes in calling within regions and distribution of source locations from correlations of calling on multiple arrays before and after the peak calling period were suggestive of blue whale migration from and toward the southeast, off Southern California and Mexico.

Fin whale calling was widely distributed in these offshore waters, with the least in the NW, in contrast to blue whales. Fin whale calling peaked in midwinter, with calling apparently from relatively local concentrations of whales. From our previous work, these fin whale call sequences appear to function as male breeding displays, and were distributed broadly in offshore waters during the winter season. These data indicate relatively large numbers of fin whales, especially if the calling we monitored was restricted to breeding males.

Humpback whale songs attributed to male breeding displays were received from December through May in an area between Southeast Alaska and Hawaii with apparent movement both southward and northward throughout that period. This suggests that some of these singing whales remain in deep water during this period, and/or that some stay in Hawaii for as little as two months.

The monitoring of low frequency whale calls using these deep water listening systems has allowed regular, non-disturbing, basin-wide assessments of the seasonal and geographic distribution of calling blue, fin and humpback whales. The function of the blue whale calling is not known, but the call sequences monitored from fin and humpback whales have been attributed to male breeding displays. Continued use of the oceanic hydrophone systems for this purpose will from the north. help confirm the patterns of vocal activity by these species in the North Pacific regions. When merged with oceanographic, meteorologic, and nutrient information about these waters, the call data will allow forecasts of the seasonal distribution of these whale species and their potential contribution to the ambient sound.

Although blue, fin, and humpback whales have variable but generally similar source levels and frequencies in these calls (i.e., Cummings and Thompson, 1971; Watkins et al., 1987; MacDonald et al., 1995; Clark and Fristrup, 1997), blue whale calls often appeared to be received over longer distances. This suggests that these calls were more consistently produced at depths that allowed better transmission via deep sound channels to the bottom hydrophones. In contrast the fin and humpback calls appeared generally to be received over relatively shorter distances, likely from whales close to the surface. If the fin whale call sequences and humpback whale songs that were monitored were male breeding displays, they would have been produced by near-surface whales (Watkins, 1981; Watkins et al., 1987; Tyack, 1981; Payne et al., 1983).

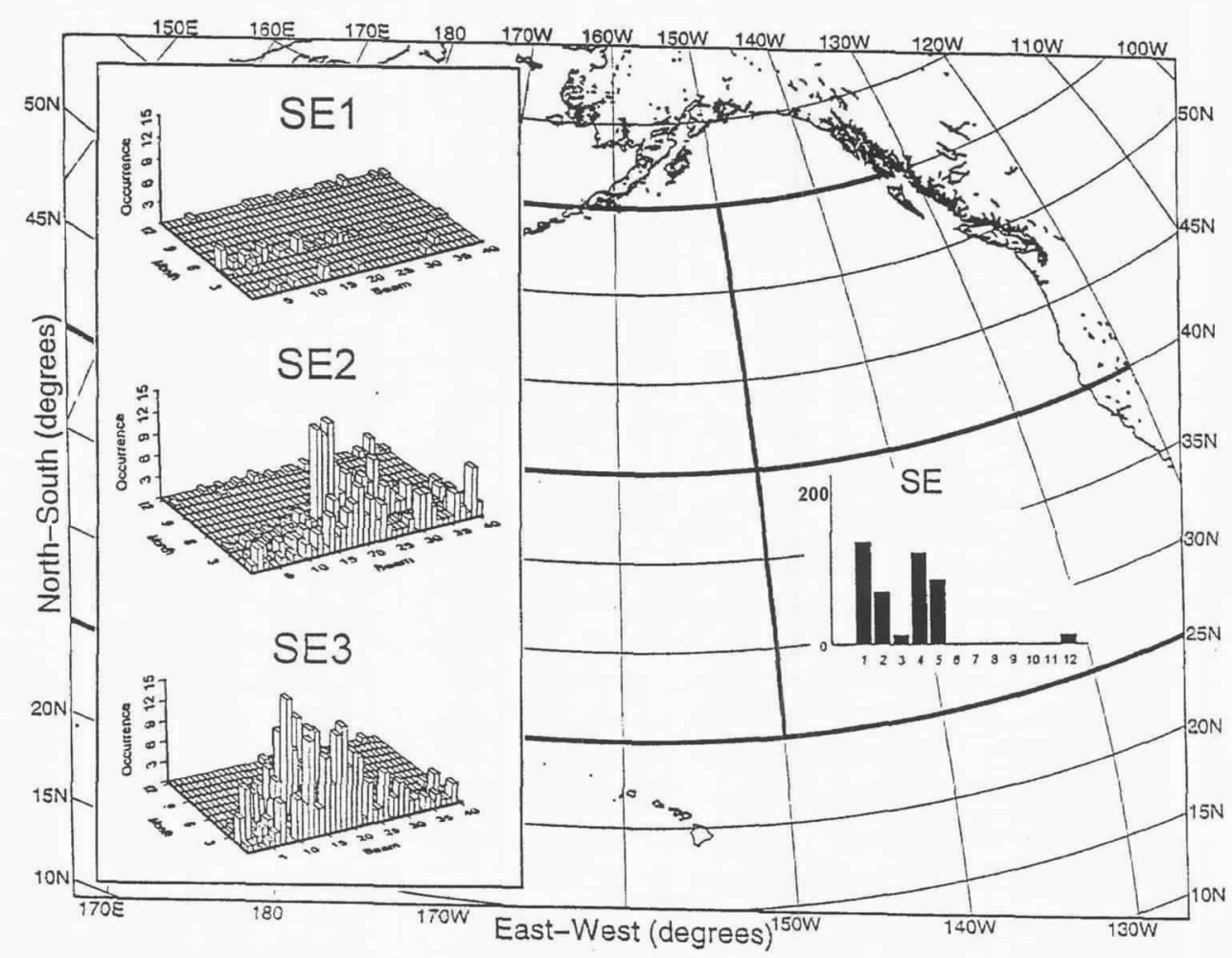

Figure 5 - The regional map shows the relative number of occurrences of humpback whale singing identified in 1996 and 1997 in the SE region, with the relative number of occurrences of songs averaged for each month. Left inset shows the distribution of singing for all SE array beams averaged for each of the 12 months and plotted as relative numbers of occurrences of songs for the different arrays. Arrays were labeled 


\section{Acknowledgments}

The encouragement and participation by personnel at Whidbey Island NOPF, Oak Harbor, WA has been appreciated over the last six years, including present and former Commands, CAPT. M. Mosier, CDR D. Geiger, CDR T. Concannon, and CDR T. Barrett. Support has been from the SERDP Council, administered currently by the U.S. Office of Naval Research. Helpful comments on this and previous versions of this report were made by each of the Commands at Whidbey NOPF, by Robert Cepek, Marilyn Dahlheim, Robert Gisiner, Christopher Clark, Robert Spindel, Dennis Conlon, and Sue Ellen Moore. This is Contribution Number 9729 from the Woods Hole Oceanographic Institution.

\section{REFERENCES}

Clark, C.W., 1995: Application of US Navy underwater hydrophone arrays for scientific research on whales. Rept. Int. Whal. Commn., 45, 210-212.

Clark, C.W. and K.M. Fristrup, 1997: Whales '95: A combined visual and acoustic survey of blue and fin whales off southern California. Rept. Int. Whal. Commn., 47, 583-600.

Cummings, W.C. and P.O. Thompson, 1971: Underwater sounds from the blue whale, Balaenoptera musculus. J. Acoust. Soc. Am., 50,1193-1198.

Cummings, W.C and P.O. Thompson, 1994: Characteristics and seasons of blue and finback whale sounds along the U.S. west coast as recorded at SOSUS stations. Abstract, J. Acoust. Soc. Am., 95, 2853.

Gagnon, C. and C.W. Clark, 1993: The use of the U.S. Navy IUSS passive sonar to monitor the movement of blue whales. Abstracts, Tenth Biennial Conf. Biol. Mar. Manm., Galveston, TX, p. 50.

McDonald, M.A., J.A. Hildebrand and S.C. Webb, 1995: Blue and fin whales observed on a seafloor array in the Northeast Pacific. J. Acoust. Soc. Am., 98, 712-721.

Moore, S.E., K.M. Stafford, M.E. Dahlheim, C.G. Fox, H.W. Braham, J.J. Polovina and D.E. Bain, 1998: Seasonal variation in fin whale call reception at five geographic areas in the North Pacific. Mar. Mamm. Sci., 14, 217-225.

Nishimura, C.E. and D.M. Conlon, 1994: IUSS Dual Use: Monitoring whales and earthquakes using SOSUS. Mar. Tech. Soc. J., 27(4), 13-21.

Northrop, J., W.C. Cummings and M.F. Morrison, 1971: Underwater $20-\mathrm{Hz}$ signals recorded near Midway Island. J. Acoust. Soc. Am., 49, 1909-1910.

Payne, K., P. Tyack and R. Payne, 1983: Progressive changes in the songs of humpback whales (Megaptera novaeangliae): a detailed analysis of two seasons in Hawaii. In: Communication and Behavior of Whales, $\mathrm{R}$. Payne, ed., AAAS Selected Symposium 76, Westview Press, Boulder CO, pp. 9-57.
Payne, R.S. and S. McVay, 1971: Songs of humpback whales. Science, 173, 585-597.

Rivers, J. A., 1997: Blue whale, Balaenoptera musculus, vocalizations from the waters off central California. Mar. Mamm. Sci., 13, 186-227.

Schevill, W.E. and B. Lawrence, 1949: Underwater listening to the white porpoise (Delphinapterus lencas). Science, 109, 143-144.

Schevill, W.E. and B. Lawrence, 1950: A phonograph record of the underwater calls of Delphinapterus leucas. Ref. No. 50-1, Woods Hole Oceanographic Institution, 3 pp., phonograph record.

Schevill, W.E. and W.A. Watkins, 1962: Whale and Porpoise Voices. A Phonograph Record. Woods Hole Oceanographic Institution, Woods Hole, MA, 24 pp., phonograph record.

Schevill, W.E. W.A. Watkins and R. H. Backus, 1964: The 20-cycle signals and Balaenoptera physalus (fin whales). In: Marine Bio-Acoustics, W.N. Tavolga, ed., Pergamon Press, New York, 147-152.

Stafford, K.M., C.G. Fox and D.S. Clark, 1998: Longrange acoustic detection and localization of blue whale calls in the northeast Pacific Ocean. J. Acoust. Soc. Am., 104, 3616-3625.

Thompson, P.O. and W.A. Friedl, 1982: A long term study of low frequency sounds from several species of whales off Oahu, Hawaii. Cetology, 45, 1-19.

Thompson, P.O., L.T. Findley, O. Vidal and W.C. Cummings, 1996. Underwater sounds of blue whales, Balaenoptera musculus, in the Gulf of California, Mexico. Mar. Mamm. Sci., 12, 288-293.

Tyack, P., 1981: Interactions between singing Hawaiian humpback whales and conspecifics nearby. Behav. Ecol. Sociobiol., 8, 105-116.

Watkins, W.A. 1981: Activities and underwater sounds of finback whales (Balaenoptera physalus). Sci. Rep Whales Res. Inst., Tokyo, 33, 83-117.

Watkins, W.A., and D. Wartzok, 1985: Sensory biophysics of marine mammals. Mar. Mamm. Sci., 1, 219260.

Watkins, W.A., P. Tyack, K.E. Moore and J.E. Bird, 1987: The $20-\mathrm{Hz}$ signals of finback whales (Balaenoptera physalus). J. Acoust. Soc. Am., 82, 901-1912.

Watkins, W.A., K.M. Fristrup and M.A. Daher, 1991: Marine animal sound database. Tech. Rep. WHOI-91-21, Woods Hole Oceanographic Institution, Woods Hole, MA, $51 \mathrm{pp}$.

Watkins, W.A., M.A. Daher, J. George, V. Ronquil and A. Stanley, 1993: Unusual whale sound tracked by Navy SOSUS. Unpublished Tech. Rep., Space and Naval Warfare Systems Command, Arlington, VA, 23. 